\title{
Molecular Characterization of Koolen De Vries Syndrome in Two Girls with Idiopathic Intellectual Disability from Central Brazil
}

\author{
Gustavo R. Nascimento ${ }^{a, b}$ Irene P. Pinto ${ }^{a, c}$ Aldaires V. de Melo ${ }^{a, c}$ \\ Damiana M. da Cruz ${ }^{a}$ Cristiano L. Ribeiro ${ }^{a, c}$ Claudio C. da Silva ${ }^{a-c}$ \\ Aparecido D. da Cruz ${ }^{a-c}$ Lysa B. Minasia, b
}

a Departamento de Biologia, Núcleo de Pesquisas Replicon, and b Programa de Pós-Graduação em Genética, Pontifícia Universidade Católica de Goiás, and 'Programa de Pós-Graduação em Biotecnologia e Biodiversidade, Universidade Federal de Goiás, Goiânia, Brazil

\section{Established Facts}

- Koolen-De Vries syndrome is a rare genetic condition caused by $17 \mathrm{q} 21.31$ microdeletion including the KANSL1 and MAPT genes.

- The main clinical features are developmental delay, facial dysmorphism, and friendly behavior. The phenotype may vary comprising cryptorchidism, scoliosis, kidney and urologic anomalies as well as epilepsy.

\section{Novel Insights}

- Our patients are 2 of 3 cases identified with a 17q21.31 microdeletion in Brazil and present with major features observed in Koolen De Vries syndrome. We believe that it is important to investigate rare syndromic disorders and try to identify the genetic causes of intellectual disability and that rare diseases demand to be published to make cases available for future studies.

- Chromosomal microarray analysis is an effective method to establish adequate genomic diagnosis of idiopathic intellectual disability providing appropriate biological information which could be beneficial for patients and medical management.

\section{Keywords}

Chromosomal microarray analysis - Copy number variation · Microdeletion 17q21.31

\section{Abstract}

Koolen de Vries syndrome (KDVS; MIM 610443) is a genomic disorder caused by a recurrent microdeletion derived from nonallelic homologous recombination mediated by flanking

\section{KARGER}

(C) 2017 S. Karger AG, Basel

E-Mail karger@karger.com

www.karger.com/msy segmental duplications. Clinical manifestations of this syndrome are characterized by intellectual disability, hypotonia, a friendly behavior, distinctive facial features, and epilepsy. Herein, we report a case of 2 girls who revealed global developmental delay, mild facial dysmorphisms, friendly behavior, and epileptic seizure with a de novo 17q21.31 microdeletion detected by chromosomal microarray analysis (CMA). Conventional cytogenetics analysis by GTG-banding showed a female karyotype $46, \mathrm{XX}$ for both girls. CMA revealed a mi-

Irene P. Pinto

Departamento de Biologia, Pontifícia Universidade Católica de Goiá Rua 235, n. 40, Bloco L, Área IV Setor Universitário

Goiânia, GO 74605-010 (Brazil)

E-Mail iplazapinto@gmail.com 
crodeletion spanning approximately $500 \mathrm{~kb}$ in 17q21.31 in both girls, encompassing the following genes: CRHR1, MGC57346, CRHR1-IT1, MAPT-AS1, SPPL2C, MAPT, MAPT-IT1, $S T H$, and KANSL1. Haploinsufficiency of one or more of these genes within the deleted region is the most probable cause of the probands' phenotype and is responsible for the phenotype seen in KDVS. CMA is a powerful diagnostic tool and an effective method to identify the de novo 17q21.31 microdeletion associated with KDVS in our probands.

๑) 2017 S. Karger AG, Basel

Koolen de Vries syndrome (KDVS; MIM610443), also known as $17 \mathrm{q} 21.31$ microdeletion syndrome, is a genomic disorder defined by peculiar facial features, including a bulbous nasal tip, global developmental delay, moderate to severe intellectual disability, hypotonia, and friendly behavior [Koolen et al., 2006, 2008]. In addition, other phenotypic features were observed including scoliosis/ kyphosis in $36 \%$ of the patients with this microdeletion, cryptorchidism (78\%), kidney and urological anomalies (32\%), as well as epilepsy described in more than $55 \%$ of the individuals [Bernardo et al., 2016]. The prevalence of KDVS varies from 1 in 13,000 and 1 in 20,000, identified as a de novo event [Egger et al., 2013]. This syndrome is caused by a recurrent microdeletion with sizes ranging from 500 to $650 \mathrm{~kb}$ at $17 \mathrm{q} 21.31$, derived from nonallelic homologous recombination (NAHR) mediated by flanking segmental duplications [Koolen et al., 2006, 2012]. The recurrent $17 \mathrm{q} 21.31$ microdeletion encompasses 5 genes CRHR1, KANSL1, MAPT, SPPL2C, and STH [Koolen et al., 2012; Egloff et al., 2014; Barone et al., 2015]. Additionally, point mutations in KANSL1 and MAPT cause the haploinsufficiency in these genes and were associated with the KDVS phenotype [Koolen et al., 2008, 2012; Zollino et al., 2012].

Herein, we report a case of 2 girls who presented with global developmental delay, mild facial dysmorphisms, friendly behavior, and epileptic seizure with a de novo 17q21.31 microdeletion detected by chromosomal microarray analysis (CMA).

\section{Case Reports}

Patient 1

The proband, an 18-year-old female and the second child of nonconsanguineous parents, was born at 38 weeks' gestation to a 22-year-old mother and 26-year-old father by cesarean section. Her birth weight and size were 2,550 g and $45 \mathrm{~cm}$, respectively. Her head circumference was $33 \mathrm{~cm}$. She presented with epilepsy. The seizure episodes began in early infancy. Talking started at 3 years of age. Physical examination of the proband revealed global developmental delay, mild intellectual disability, and friendly behavior. She also had mild facial dysmorphisms, such as low-set ears, lop/ cupped ears, a long face, and a tubular or 'pear-shaped' nose with a bulbous nasal tip. Her family history was unremarkable (Fig. 1a).

\section{Patient 2}

The proband, a 22-year-old girl, was born to nonconsanguineous parents at 42 weeks' gestation to a 32 -year-old mother and 48 -year-old father. At birth, her weight was $2,770 \mathrm{~g}$ and her crownheel length was $47 \mathrm{~cm}$. Her head circumference was $60 \mathrm{~cm}$. The child was delivered by cesarean section. She was born with a clubfoot, muscle weakness, and hypotonia. At 7 months, she manifested epilepsy. At physical examination, the patient revealed global developmental delay with cognitive and speech delay. Her facial dysmorphisms included a long face, lop/cupped ears, and a bulbous nose. The family history had no remarkable information (Fig. 1a).

\section{Material and Methods}

Karyotyping at $>550$-band resolution was carried out with peripheral blood samples from the patients using conventional cell culture, harvesting, and GTG-banding following standard procedures. Chromosomal analyses were done using the IKAROS ${ }^{\circledR}$ software (Metasystems Corporation, Germany).

Genomic DNA was isolated from whole blood using QIAamp ${ }^{\circledR}$ DNA Mini kit (Qiagen, Germany). CMAs were performed for both patients and their parents using GeneChip ${ }^{\circledR}$ CytoScanHD $^{\text {TM }}$ (Affymetrix, Santa Clara, CA, USA) according to the manufacturer's instructions. The array was designed specifically for cytogenetic research, including approximately 2,696,550 CNV markers, 743,304 SNP markers, and >1,953,246 non-polymorphic markers. CEL files obtained by scanning the arrays were analyzed using the Chromosome Analysis Suite software (Affymetrix). The CNVs found in the 2 patients and their parents were compared with genomic variants in public databases, including DGV, DECIPHER, OMIM, and CytoScanHD ${ }^{\text {TM }}$ Array Database.

17q21.31 Low-Copy Repeat Structure Analysis

Using the Segmental Duplication track (http://genome.ucsc. $\mathrm{edu} /$ ) from the genome browser (Human Genome Build 37.1), we performed an analysis of duplicated genomic sequences including known low-copy repeats (LCRs) (segmental duplication $>1 \mathrm{~kb}$ of non-RepeatMasked sequence with over $98 \%$ similarity), comparing an approximately $1.69-\mathrm{Mb}$ region surrounding the proximal $17 \mathrm{q} 21.31$ locus (chr17:43,085,534-44,776,171). This region represented 3 times of the CNV size.

\section{Results}

Karyotyping showed no visible numerical or structural alterations in the chromosomes. Both girls showed female karyotypes (46,XX). CMA revealed a de novo microdeletion in both girls spanning approximately $500 \mathrm{~kb}$
156

Mol Syndromol 2017;8:155-160 DOI: $10.1159 / 000456910$
Nascimento/Pinto/de Melo/da Cruz/ Ribeiro/da Silva/da Cruz/Minasi 


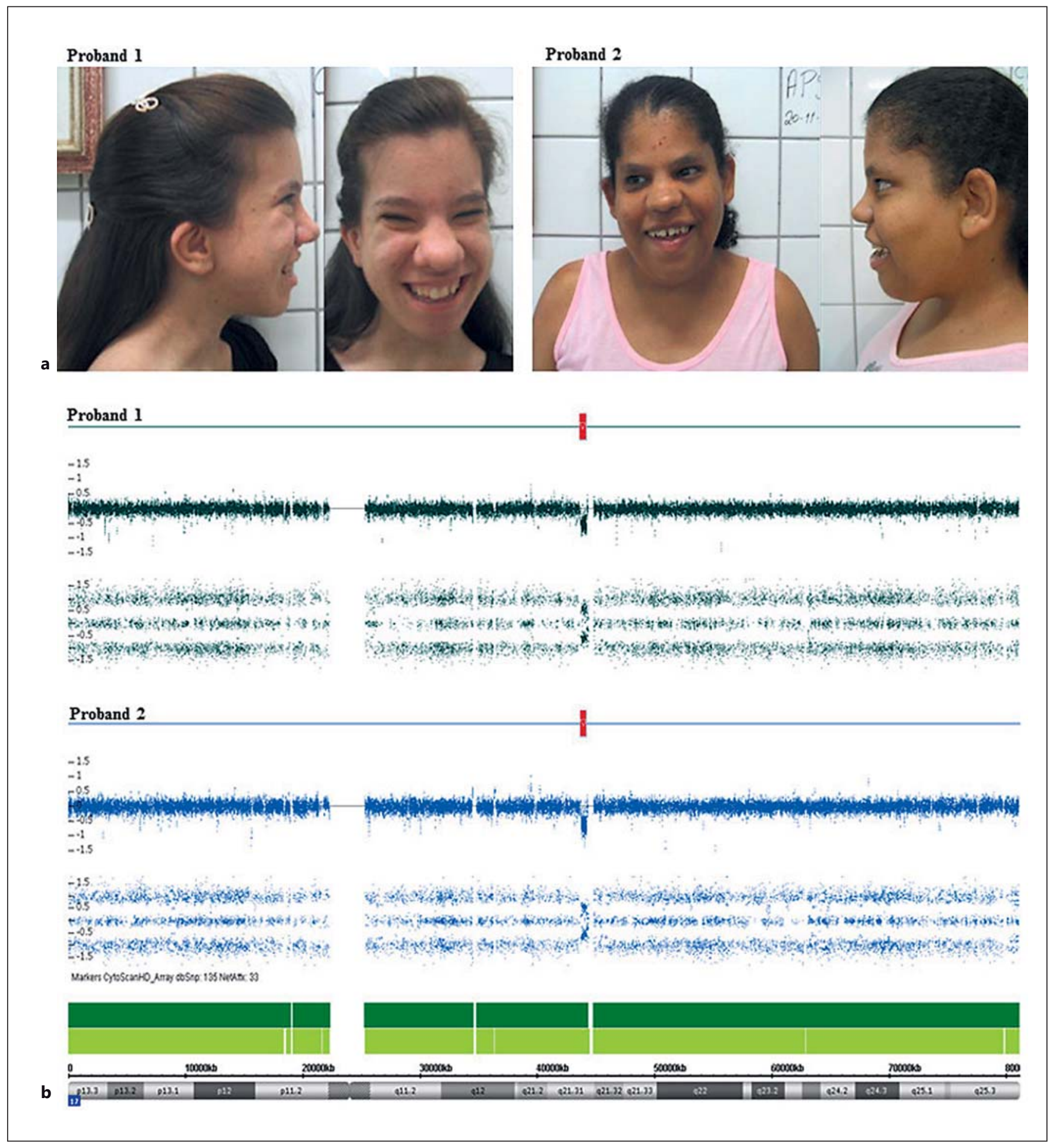

Fig. 1. Phenotype and molecular features of the 2 probands with KDVS. a Proband 1: facial dysmorphisms such as low-set ears, long face, a bulbous nasal tip are shown. Proband 2: dysmorphic features including a long face, lop/cupped ears, and a bulbous nose are shown. $\mathbf{b}$ CMA of the 17q21.31 microdeletion. CMA data from proband 1 and proband 2 showing a de novo $0.56-\mathrm{Mb}$ and $0.51-\mathrm{Mb}$ microdeletion, respectively, indicated by red blocks.

Molecular Characterization of Koolen De Vries Syndrome
Mol Syndromol 2017;8:155-160

DOI: $10.1159 / 000456910$ 


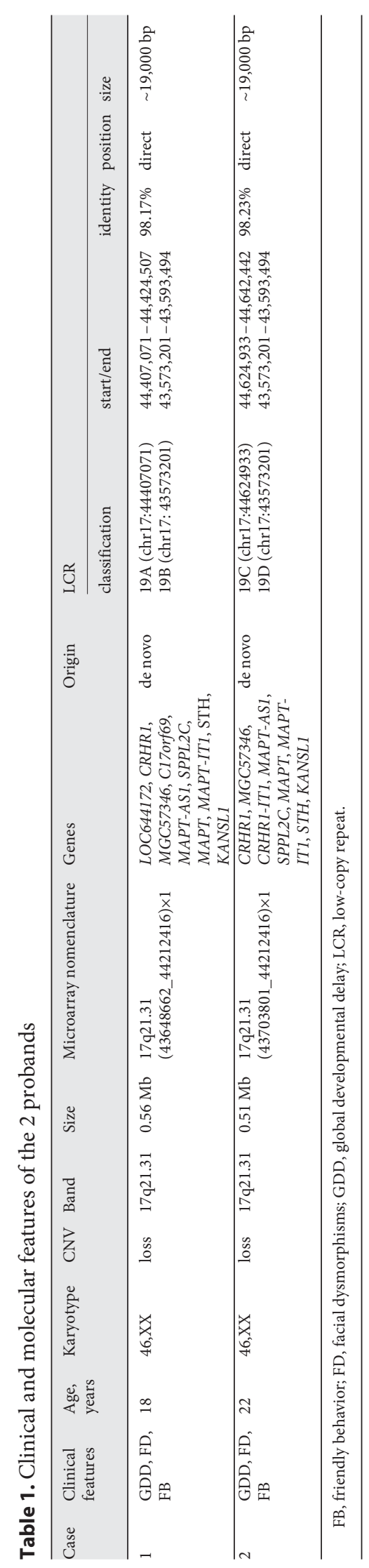

in 17q21.31, encompassing the following genes: CRHR1, MGC57346, CRHR1-IT1, MAPT-AS1, SPPL2C, MAPT, MAPT-IT1, STH, and KANSL1 (Fig. 1b; Table 1). Parental CMA analysis confirmed the deletions to be de novo events.

Analyses of the rearranged $17 \mathrm{q} 21.31$ chromosomal region showed 2 major LCR families within the studied region. Each LCR family was named as 19A-19B and 19C$19 \mathrm{D}$ with approximately $19 \mathrm{~kb}$ flanking the disease locus. The LCRs were directly repeated and shared $98.2 \%$ identity (Fig. 2; Table 1).

\section{Discussion}

Intellectual disability is the most common developmental disorder, affecting 2-3\% of the general population [Bernardini et al., 2010]. The frequency would probably be higher, if appropriate genetic testing and diagnostic procedures would be employed. According to Qiao et al. [2014], submicroscopic CNVs occur in 5-15\% of the cases with intellectual disability. Thus, screening for submicroscopic chromosomal rearrangements using genomic microarrays in clinical practice have improved the diagnostic yield up to $10-25 \%$ in patients with intellectual disability [Battaglia et al., 2013].

Here, we report the cases of 2 girls presenting with several phenotypic traits commonly seen in KDVS, such as intellectual disability, dysmorphic facial features, friendly behavior, epilepsy, and a de novo 17q21.31 microdeletion harboring the genes KANSL1, CRHR1, and MAPT - characterized as the main genes associated with the syndrome.

Molecular mechanisms such as NAHR flanked by segmental duplications may collaborate to the formation of chromosomal rearrangements, leading to deleted or duplicated genomic segments. This finding demonstrates the importance of genomic instability in the recurrence of genomic disorders [Vlchova et al., 2014]. NAHR-mediated deletion has been observed as a potential mechanism in a considerable number of microdeletion syndromes, including the 17q21.31 microdeletion [Koolen et al., 2006]. We identified 2 major LCR families flanking the genomic rearrangement of $17 \mathrm{q} 21.31$ microdeletions. These findings show that LCRs may contribute to the increase in the susceptibility of CNV formation by NAHR, generating recurrent deletions in the $17 \mathrm{q} 21.31$ region.

The KANSL1 gene, a member of a histone acetyltransferase complex, encodes a nuclear protein which acts as a subunit of 2 protein complexes involved in histone acetylation, especially the $\mathrm{H} 4$ subunit. This gene is expressed 


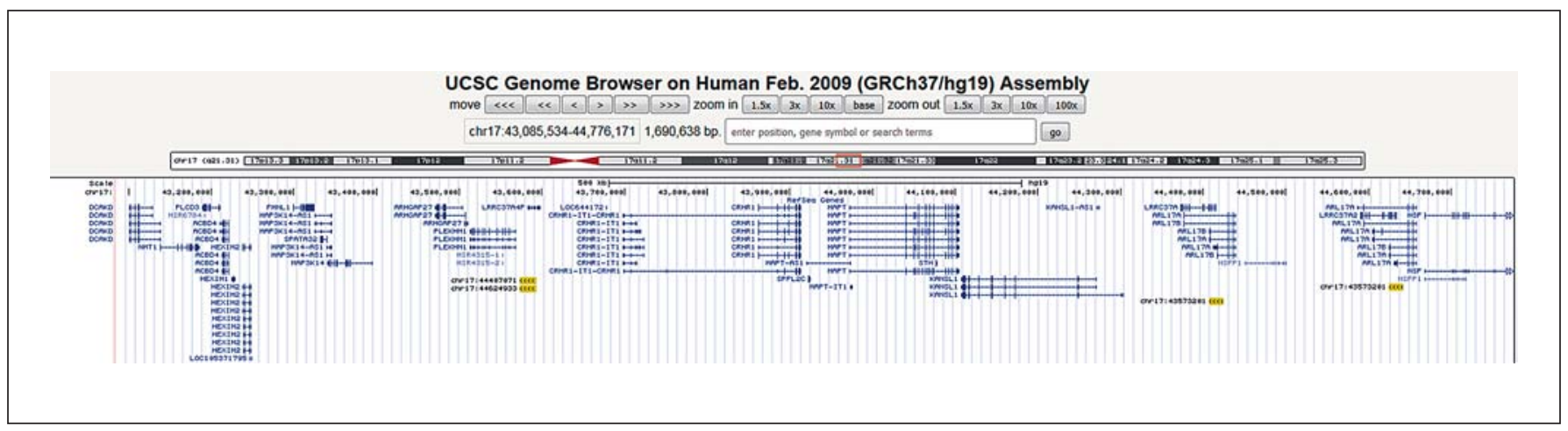

Fig. 2. Schematic representation of the $17 \mathrm{q} 21.31$ chromosomal region and summary of segmental duplication analyses. Two major LCR families [19A (chr17:44407071), 19B (chr17:43573201), 19C (chr17:44624933), and 19D (chr17:43573201)] in this region are represented by yellow blocks. Genes within this region are represented by blue lines.

in human tissues, including the central nervous system [Moreno-Igoa et al., 2015]. The haploinsufficiency of the KANSL1 gene is sufficient to cause a KDVS phenotype. Koolen et al. [2012] and Zollino et al. [2012] detected a de novo point mutation in KANSL1 in patients with failure to thrive in infancy, hypotonia, developmental delay with mild to moderate intellectual disability, and dysmorphic facial features.

The encoded microtubule-associated protein Tau (MAPT) is abundant in the axons of neurons and is highly expressed in the brain [Ballatore et al., 2007]. The Tau protein is a regulator of microtubule dynamics and plays a role in microtubule assembly and stabilization. This protein functions as an essential nuclear player in the protection of neuronal genomic DNA integrity under reactive oxygen species producing heat stress in primary neuronal cultures [Violet et al., 2014]. Besides, hyperphosphorylation and aggregation of the Tau protein leads to the formation of neurofibrillary tangles observed in neurodegenerative disorders (tauopathies) [Violet et al., 2014]. Mutations in the MAPT gene are involved in behavioral phenotypes and in certain neurodegenerative diseases [Koolen et al., 2008]. In addition, haploinsufficiency of the MAPT gene has been implicated in the neurocognitive functioning and has been associated with the main clinical features observed in individuals with 17q21.31 microdeletion [Koolen et al., 2006; Shaw-Smith et al., 2006; Wray, 2013].

The corticotropin-releasing hormone receptor 1 gene (CRHR1) encodes a $G$ protein-coupled receptor that binds neuropeptides of the corticotropin-releasing hormone family, which are major regulators of the hypothalamic-pituitary-adrenal pathway and mediate stress-in-

Molecular Characterization of Koolen De

Vries Syndrome duced endocrine, behavioral, autonomic, and immune responses [Yang et al., 2015]. According to the authors, peculiar genes within the 17q21.31 microdeletion conferring some seizure susceptibility and the haploinsufficiency of the $C R H 1$ gene may predispose to having seizures, especially infantile spasms [Wray, 2013; Bernardo et al., 2016]. Furthermore, CRHR1 signaling is involved in memory and learning, and a dosage deficit of this gene may contribute to the presence of global developmental delay [Sharkey et al., 2009].

CMA analysis is a powerful diagnostic tool and it is an effective method to identify the 17q21.31 microdeletion associated with KDVS in our probands with idiopathic intellectual disability. To our knowledge, the cases reported here are similar to the first case of 17q21.31 microdeletion identified in Central Brazil [Dornelles-Wawruk et al., 2013], since CMA technology has been employed in the region, confirming its usefulness to increase the diagnostic yield of undiagnosed intellectual disability. The authors believe that further investigation is needed to allow adequate phenotypic classification of probands, especially in the event of undiagnosed rare genomic diseases. Although the phenotype found in our probands shows similar features of KDVS, only additional gene expression studies will confirm the association between these genes and KDVS. Thus, international collaborative studies will need to be designed and carried out to increase the likelihood of finding a large cohort of patients to validate the findings of individual studies. Notwithstanding, CMA is an efficient method to delineate phenotypic variations, allowing adequate clinical management and better follow-up of the probands and their families.

Mol Syndromol 2017;8:155-160 159 


\section{Acknowledgments}

The authors wish to thank Dr. Rinaldo W. Pereira and the Rede ExeGenes for supporting the improvement of genetic diagnosis in Central Brazil. This work was sponsored by grants from CNPq (Edital 031/564465/2010-10) and FAPEG (2011.6002.19.1847.1134-03).

\section{Statement of Ethics}

This study was approved by the Institutional Ethics Committee. The family provided written informed consent.

\section{Disclosure Statement}

The authors declare that they have no competing interests.

\section{References}

Ballatore C, Lee VM, Trojanowski JQ: Tau-mediated neurodegeneration in Alzheimer's disease and related disorders. Nat Rev Neurosci 8:663-672 (2007).

Barone C, Novelli A, Capalbo A, Del Grano AC, Giuffrida MG, et al: An additional clinical sign of $17 \mathrm{q} 21.31$ microdeletion syndrome: preaxial polydactyly of hands with broad thumbs. Am J Med Genet A 167:1671-1673 (2015).

Battaglia A, Doccini V, Bernardini L, Novelli A, Loddo S, et al: Confirmation of chromosomal microarray as a first-tier clinical diagnostic test for individuals with developmental delay, intellectual disability, autism spectrum disorders and dysmorphic features. Eur J Paediatr Neurol 17:589-599 (2013).

Bernardini L, Alesi V, Loddo S, Novelli A, Bottillo I, et al: High-resolution SNP arrays in mental retardation diagnostics: how much do we gain? Eur J Hum Genet 18:178-185 (2010).

Bernardo P, Madia F, Santulli L, Del Gaudio L, Caccavale C, et al: $17 \mathrm{q} 21.31$ microdeletion syndrome: description of a case further contributing to the delineation of Koolen-de Vries syndrome. Brain Dev 38:663-668 (2016).

Dornelles-Wawruk H, Pic-Taylor A, Rosenberg C, Krepischi AC, Safatle HP, et al: Complex phenotype associated with $17 \mathrm{q} 21.31$ microdeletion. Mol Syndromol 4:297-301 (2013).
Egger JI, Wingbermühle E, Verhoeven WM, Dijkman M, Radke S, et al: Hypersociability in the behavioral phenotype of $17 \mathrm{q} 21.31$ microdeletion syndrome. Am J Med Genet A 161A:21-26 (2013).

Egloff M, Encha-Razavi F, Garel C, BonnièreDarcy M, Millischer AE, et al: 17q21.31 microdeletion: brain anomalies leading to prenatal diagnosis. Cytogenet Genome Res 144: 178-182 (2014).

Koolen DA, Vissers LE, Pfundt R, de Leeuw N, Knight SJ, et al: A new chromosome 17q21.31 microdeletion syndrome associated with a common inversion polymorphism. Nat Genet 38:999-1001 (2006).

Koolen DA, Sharp AJ, Hurst JA, Firth HV, Knight SJ, et al: Clinical and molecular delineation of the $17 \mathrm{q} 21.31$ microdeletion syndrome. J Med Genet 45:710-720 (2008).

Koolen DA, Kramer JM, Neveling K, Nillesen WM, Moore-Barton HL, et al: Mutations in the chromatin modifier gene KANSL1 cause the $17 \mathrm{q} 21.31$ microdeletion syndrome. Nat Genet 44:639-641 (2012).

Moreno-Igoa M, Hernández-Charro B, BengoaAlonso A, Pérez-Juana-del-Casal A, RomeroIbarra C, et al: KANSL1 gene disruption associated with the full clinical spectrum of $17 \mathrm{q} 21.31$ microdeletion syndrome. BMC Med Genet 16:68 (2015).

Qiao Y, Mercier E, Dastan J, Hurlburt J, McGillivray B, et al: Copy number variants (CNVs) analysis in a deeply phenotyped cohort of individuals with intellectual disability (ID). BMC Med Genet 15:82 (2014).
Sharkey FH, Morrison N, Murray R, Iremonger J, Stephen J, et al: 17q21.31 microdeletion syndrome: further expanding the clinical phenotype. Cytogenet Genome Res 127:61-66 (2009).

Shaw-Smith C, Pittman AM, Willatt L, Martin H, Rickman L, et al: Microdeletion encompassing MAPT at chromosome $17 \mathrm{q} 21.3$ is associated with developmental delay and learning disability. Nat Genet 38:1032-1037 (2006).

Violet M, Delattre L, Tardivel M, Sultan A, Chauderlier A, et al: A major role for Tau in neuronal DNA and RNA protection in vivo under physiological and hyperthermic conditions. Front Cell Neurosci 8:84 (2014).

Vlckova M, Hancarova M, Drabova J, Slamova Z, Koudova M, et al: Monozygotic twins with 17 q21.31 microdeletion syndrome. Twin Res Hum Genet 17:405-410 (2014).

Wray C: $17 \mathrm{q} 21.31$ microdeletion associated with infantile spasms. Eur J Med Genet 56:59-61 (2013).

Yang G, Zou LP, Wang J, Shi XY, Yang XF, et al: Association analysis of polymorphisms of the CRHR1 gene with infantile spasms. Mol Med Rep 12:2539-2546 (2015).

Zollino M, Orteschi D, Murdolo M, Lattante S, Battaglia D, et al: Mutations in KANSL1 cause the $17 \mathrm{q} 21.31$ microdeletion syndrome phenotype. Nat Genet 44:636-638 (2012). 